\title{
Indicadores para a Análise da Dinâmica Inovativa em Arranjos Produtivos Locais: Uma Análise Exploratória Aplicada ao Arranjo Eletrometal-Mecânico de Joinville/SC
}

\author{
- Fabio Stallivieri* - Renato Ramos Campos** - Jorge noguelra de Palva Britto***
}

\begin{abstract}
RESUMO
A partir da recente literatura sobre arranjos produtivos locais, este trabalho procura construir indicadores para a análise destas aglomerações. Os indicadores foram elaborados com base em informações obtidas em questionário aplicado em campo, numa amostra de 83 empresas, dos mais diversos portes, atuando no arranjo eletrometal-mecânico da região de Joinville/SC. Os 24 indicadores selecionados foram divididos em quatro grupos relacionados ao esforço tecnológico, à aprendizagem tecnológica, à cooperação e ao desempenho tecnológico. Com base nos indicadores, procurou-se utilizar técnicas estatísticas de Análise Multivariada de modo a caracterizar os principais fatores que diferenciam as capacitações das firmas e a identificar os diversos agrupamentos de empresas no interior de um arranjo produtivo local. Com os resultados obtidos, foi possível identificar um núcleo de empresas dinâmicas que estimulam as capacitações tecnológicas do arranjo.
\end{abstract}

\section{Palavras-Chave}

Indicadores para análise de APLs, núcleo dinâmico, eletrometal-mecânico de Joinville/SC

\begin{abstract}
Starting from the evidences of an updated literature about Local Production Systems, the paper tries to identify some indicators that can be used to analyze those agglomerations. The indicators were based on data collected from a questionnaire applied on a sample of 83 firms, with different sizes, inserted in the electrical and metal-mechanical agglomeration located in the region of Joinville-SC. The 24 indicators selected were divided in four groups, related with aspects of technological efforts, technological learning, technological cooperation and technological performance. The indicators were manipulated through the use of multivariate techniques, in order to identify the main factors that could be used to differentiate firms' capabilities and to generate different clusters comprising groups of enterprises in the agglomeration which similar characteristics regarding those factors. Moreover, the analysis performed also permits the identification of a core of dynamic firms that can stimulate the strengthening of technological capabilities in the agglomeration.
\end{abstract}

\section{KEYWORDS}

indicators for local production arrangements, core of dynamic firms, electrical and metal-mechanical arrangement

\section{JEL CLASSIFICATION}

O33, L67

* Doutorando em economia pela Universidade Federal Fluminense. Bolsista do programa de Bolsas Nota I0 da FAPERJ. Endereço para contato: Rua das Laranjeiras, 102, ap. 403, Laranjeiras, Rio de Janeiro - RJ. CEP: 22204-000. E-mail: fabio_stallivieri@yahoo.com.br.

* Professor associado ao Departamento de Economia da UFSC. Endereço para contato: Rua General Estilac Leal, 129, Bloco B, AP.105, Coqueiros, Florianópolis - SC. CEP: 88080-760. E-mail: recampos@cse.ufsc.br.

$\star \star \star$ Professor do Departamento de Economia da UFF e Bolsista do CNPq. Endereço para contato: Praia de Botafogo, 48, 28 Botafogo, Rio de Janeiro - RJ. CEP: 22650-040. E-mail: jbrit@terra.com.br.

(Recebido em setembro de 2006. Aceito para publicação em agosto de 2007). 


\section{$1 \quad$ INTRODUÇÃO}

Nos últimos anos, a realização de diversos estudos empíricos, acompanhada de uma intensa discussão analítica, tem permitido avançar em termos de uma definição mais rigorosa do conceito de Arranjos Produtivos Locais (APLs). Em um sentido amplo, estes arranjos podem ser associados à aglomeração espacial de agentes econômicos, políticos e sociais, os quais se encontram envolvidos com um conjunto específico de atividades econômicas, apresentando vínculos e interdependência. Por meio desses vínculos, origina-se um processo de aprendizagem que possibilita a introdução de inovações de produtos, processos e formatos organizacionais, gerando maior competitividade para as empresas integradas ao arranjo. A formação de APLs está particularmente associada a trajetórias históricas de formação de vínculos territoriais (regionais e locais), a partir de uma base social, cultural, política e econômica comum. Adicionalmente, os arranjos podem também ser concebidos como microunidades capazes de proporcionar o fortalecimento e a dinamização de sistemas de inovação em nível setorial, regional e nacional.

A abordagem metodológica de arranjos e sistemas produtivos locais destaca o papel central da inovação e do aprendizado interativo, como fatores de competitividade sustentada, constituindo uma alternativa analítica ao foco tradicional em setores econômicos e empresas individuais (LASTRES; CASSIOLATO, 2003, p.3). Nessa perspectiva analítica, particular ênfase é atribuída à investigação de processos de aprendizagem, cooperação e inovação que ocorrem em espaços geográficos específicos. Porém, a falta de estatísticas e informações sistematizadas sobre essas aglomerações tem motivado o desenvolvimento de análises empíricas (REDESIST, 2004), cuja importância desdobra-se em duas direções principais. Por um lado, essas análises possibilitam uma compreensão mais detalhada do fenômeno, particularmente por meio da utilização de técnicas estatísticas e da definição de indicadores que permitam captar a natureza específica dos processos de cooperação, aprendizado e capacitação que ocorrem em escala local. Por outro lado, a realização de estudos empíricos constitui também uma oportunidade para testar a aplicabilidade de conceitos que possibilitem o maior "refinamento" da concepção mais geral de arranjos e sistemas produtivos e inovativos locais.

Este trabalho procura, num primeiro momento, desenvolver um conjunto de indicadores relacionados ao esforço tecnológico, à aprendizagem tecnológica, à cooperação e ao desempenho tecnológico, para as firmas inseridas em arranjos produtivos locais, a partir do questionário" utilizado no projeto "MPEs em Arranjos Produtivos Locais

1 Questionário e resultados da pesquisa disponíveis no CD relatório final do Programa de financiamento de bolsas de mestrado vinculadas à pesquisa Micro e Pequenas Empresas em Arranjos Produtivos Locais no Brasil. Coordenação: Renato Ramos Campos. Convênio UFSC/SEBRAE-NA, 2004. 
no Brasil", realizado pela UFSC e SEBRAE-NA e em pesquisas da RedeSist. ${ }^{2}$ Como exercício empírico, procura-se calcular e analisar o conjunto de indicadores para uma amostra de 83 empresas do arranjo eletrometal-mecânico de Joinville/SC, mediante a utilização de técnicas estatísticas de análise multivariada. Adicionalmente, com base na aplicação dessas técnicas, é identificado um determinado "núcleo dinâmico" do arranjo, formado por um conjunto de empresas com patamares superiores de capacitação, aprendizado e desempenho inovativo. Tais empresas apresentam maior capacidade de indução do aprendizado interativo por meio de relacionamentos interindustriais, os quais geram importantes efeitos spillovers que possibilitam a sustentabilidade do dinamismo do arranjo como um todo.

O artigo está dividido em cinco seções, além desta introdução. A primeira seção apresenta, de forma sucinta, o referencial analítico da investigação, ressaltando determinadas características dos processos de inovação, aprendizado e cooperação no interior de Arranjos Produtivos Locais possíveis de serem discutidas a partir da construção de indicadores. A segunda seção descreve o conjunto de indicadores utilizados para analisar estes processos no caso investigado. Na terceira seção, desenvolve-se a análise multivariada dos indicadores, identificando-se os fatores que diferenciam as empresas da amostra, os agrupamentos de firmas com capacitações similares e o núcleo de empresas dinâmicas do arranjo. A quarta seção destaca os processos de aprendizagem, inovação e cooperação do núcleo dinâmico e as interações desenvolvidas, no local, por essas empresas. A quinta seção apresenta as conclusões do trabalho.

\section{REFERENCIAL ANALÍTICO}

A importância crescente atribuída à consolidação de práticas cooperativas e aos processos de aprendizado por interação está vinculada à visão sistêmica do processo de inovação. Nesta perspectiva, a capacidade de geração, difusão e utilização de novos conhecimentos consolida-se como um processo que transcende a esfera da firma individual e passa a depender da contínua interação entre firmas e destas com outras organizações e instituições que constituem sistemas de inovação em diferentes âmbitos (VARGAS, 2002). Em particular, esse modelo interativo de inovação ressalta a relevância da cooperação entre firmas e demais instituições e, portanto, o papel dos vínculos e redes envolvendo diferentes organizações.

2 A Rede de Sistemas Produtivos e Inovativos Locais (RedeSist) é uma rede de pesquisa interdisciplinar, sediada no Instituto de Economia da Universidade Federal do Rio de Janeiro, e que conta com a participação de várias universidades e institutos de pesquisa no Brasil, além de manter parcerias com outras instituições do exterior (LASTRES; CASSIOLATO, 2003). 
A aglomeração territorial de empresas em torno de arranjos ou sistemas produtivos localizados tende a facilitar o engajamento desses atores em processos de aprendizado interativo. Nesse tipo de ambiente, o conhecimento tende a se tornar incorporado não somente nas qualificações individuais e nos procedimentos e rotinas das organizações, como também no próprio ambiente local ou nos vínculos de interação entre os diferentes atores e desenhos institucionais. A habilidade das empresas em criar conhecimento vai capacitá-las a interagir com os demais atores locais num processo de aprendizado coletivo, no qual conhecimentos que são em parte codificados e em parte tácitos são trocados e utilizados. Nesse aspecto, capacitaçôes localizadas refletem-se no conhecimento incorporado em indivíduos, empresas e na própria estrutura institucional presente em sistemas produtivos territoriais.

Não obstante a percepção sobre a importância crescente que assumem as práticas cooperativas para o aprendizado localizado no âmbito de aglomeraçóes produtivas, verifica-se que existem ainda lacunas consideráveis na análise tanto das formas de mensuração destes processos, como do seu impacto efetivo sobre o desempenho inovativo de empresas articuladas em torno de arranjos produtivos locais. Nesse sentido, é possível ressaltar algumas "dimensões" fundamentais do processo de consolidação de práticas cooperativas e seus desdobramentos em termos do fortalecimento de mecanismos coletivos de aprendizado para avaliar as possibilidades de um determinado arranjo evoluir ao longo de uma trajetória "virtuosa" de fortalecimento da capacitação inovativa dos agentes dos agentes inseridos no APL.

Cabe destacar três suposições básicas que orientam o esforço de investigação realizado. A primeira delas baseia-se na constatação de que os APLs constituem um lócus de aglutinação e criação de competências por meio de processos coletivos de aprendizado institucionalmente condicionados. A segunda suposição decorre naturalmente da anterior e pressupõe que o mapeamento e a avaliação das práticas cooperativas são fundamentais para a compreensão das características dos processos de aprendizado em APLs. A terceira suposição procura instrumentalizar a anterior, ressaltando a articulação existente entre consolidação de práticas cooperativas, aprofundamento do aprendizado por interação e o fortalecimento da competitividade e capacitação dos agentes.

Adicionalmente, é importante considerar que os APLs não devem ser concebidos como estruturas monolíticas, nas quais as forças que comandam uma determinada "dinâmica interna" apontam necessariamente para uma "convergência" ou "equalização" das estratégias e dos níveis de capacitação dos agentes em seu interior. Pelo contrário, as evidências sugerem que esses arranjos são estruturas intrinsecamente complexas e heterogêneas, cujos agentes possuem características assimétricas, vinculadas à consolidação de competências técnicas e cognitivas específicas, que con- 
dicionam as possibilidades de interação mútua entre eles. ${ }^{3}$ Articulam-se através de redes de relacionamentos que conformam uma determinada divisão de trabalho ou determinada "estrutura de governança", numa concepção mais institucionalista - interna a cada arranjo. Em função das características desse sistema de divisão de trabalho, define-se um determinado grau de interdependência técnica e uma logística interna ao arranjo, vinculada à presença de diversos tipos de sinergias entre as atividades realizadas.

A hipótese de que os arranjos produtivos são estruturas intrinsecamente heterogêneas afeta diretamente a possibilidade de os mesmos operarem como instância de mediação entre a firma e o ambiente externo, que amplia a capacidade de absorção de conhecimentos potencialmente úteis para o reforço da eficiência e da competitividade dos agentes. Nesse sentido, é útil considerar distinção entre fontes internas e externas de conhecimentos apropriados no processo de aprendizado, ressaltada na análise de Cohen e Levinthal (1989), na qual a ampliação do estoque de conhecimentos é definida como uma função dos investimentos em P\&D da firma e de "fontes externas" de conhecimentos, e pode ser expressa por meio da equação $Z=$ $M_{i}+Y_{i}\left(\theta \sum M_{j}+\beta T\right)$, onde:

$Z=$ ampliação do estoque de conhecimentos da firma $i$;

$M_{i}=$ investimento da firma em $\mathrm{P} \& \mathrm{D}$;

$Y_{i}=$ capacidade de absorção do conhecimento externo;

$M_{j}=$ investimentos de outras firmas em P\&D;

$\theta=$ medida de spillover $(0 \leq \theta \leq 1)$;

$\beta T=$ conhecimento externo à indústria potencialmente absorvível pela firma.

Cohen e Levinthal ressaltam que a importância dos gastos em P\&D realizados por uma firma particular refere-se não apenas ao reforço da sua "capacidade de absorção" de conhecimentos externos, mas também à possibilidade de ela identificar oportunidades tecnológicas capazes de aumentar sua eficiência e lucratividade. ${ }^{4}$ Dois fatores

3 Essa característica tende a ser ainda mais marcante no caso brasileiro, dada a "heterogeneidade estrutural" inerente à base industrial, que se reflete em expressivos diferenciais de eficiência e capacitação em termos inter e intrassetoriais (FERRAZ et alli, 1996).

4 Algumas observações relativas aos componentes da equação são ilustrativas. Quanto à capacidade de absorção, verifica-se que ela se localiza no intervalo $O \leq Y \leq 1$, o qual expressa duas situações-limite: na primeira $(\Upsilon=1)$, a firma é capaz de absorver todo o conhecimento que se encontra disponível como domínio público; na segunda $(\Upsilon=0)$, nenhum conhecimento externo é absorvido. Essa capacidade de absorção é função não apenas dos investimentos em P\&D realizados in-house, mas também de uma variável $\beta$ que expressa a "adequação" do conhecimento externo às necessidades da firma. Assim, a apropriação do conhecimento externo é modulada pelos valores de $\Upsilon$ e $\beta$, que expressam, respectivamente, uma determinada capacidade de absorção (que é função dos próprios gastos em P\&D realizados internamente) e a "adequação" do conhecimento externo às necessidades da firma. 
que afetam a exploração de oportunidades tecnológicas são incorporados ao modelo. O primeiro deles diz respeito a uma determinada "quantidade" de conhecimentos externos, que podem se converter em fontes de novas oportunidades. Essa possibilidade expressa-se no valor da variável $T$, cuja definição é suficientemente ampla para abarcar conhecimentos provenientes de laboratórios públicos, universidades e de fornecedores de insumos e equipamentos. $\mathrm{O}$ segundo fator, não captado diretamente na equação, e sim na relação que articula a expansão do estoque de conhecimentos da firma à ampliação de sua rentabilidade, refere-se à maneira como novos conhecimentos afetam a performance tecnológica dos produtos e processos da firma em questão.

Com base no modelo de Cohen e Levinthal, é possível tecer alguns comentários sobre impactos da consolidação de arranjos produtivos locais em termos do aprofundamento de mecanismos de aprendizado. Basicamente, os arranjos redefinem a dicotomia entre fontes "internas" e "externas" de conhecimentos, na medida em que conformam uma instância intermediária de interação entre agentes que possibilita uma "formatação" desses conhecimentos em função das exigências do processo competitivo, através da integração de competências complementares. Considerando o modelo proposto, três impactos principais podem ser mencionados. Em primeiro lugar, o estabelecimento de laços sistemáticos entre firmas aumenta a capacidade de absorção de cada uma delas para um mesmo montante de esforço inovativo realizado na medida em que favorece a compatibilização dos padrões cognitivos e dos procedimentos de busca adotados pelos diferentes agentes. Em segundo lugar, o efeito "vazamento" (spillover) associado às fontes externas de conhecimento tende a ser reforçado, devido à existência de canais sistemáticos de interligação entre os diversos agentes locais. Em terceiro lugar, o intercâmbio sistemático de informações entre agentes ao nível local favorece maior coordenação das estratégias implementadas localmente. Em consequência, os conhecimentos gerados tendem a estar mais bem calibrados em relação às necessidades das firmas inseridas no arranjo, o que favorece o processo de absorção.

A partir da menção a esses impactos pode-se argumentar que a geração de diversos ganhos de eficiência mencionados na literatura sobre arranjos produtivos locais sejam ganhos estritamente estáticos associados à geração de economias de escala e escopo em escala local, sejam ganhos de natureza dinâmica, decorrentes do aprofundamento do aprendizado e do fortalecimento de capacitações inovativas - estaria relacionada a dois aspectos fundamentais: (i) a conformação estrutural desses arranjos, a partir da qual estrutura-se uma "rede" de relacionamentos que possibilita o intercâmbio e integração de conhecimentos e competências; (ii) estratégias de relacionamentos dos agentes integrados aos mesmos, as quais se encontram condi- 
cionadas pelas complementaridades de ativos e competências (TEECE et alli, 1994) e pela intensidade das pressões competitivas advindas do ambiente setorial.

Quanto ao primeiro aspecto, as evidências levantadas em diversos estudos empíricos sugerem que a conformação estrutural desses arranjos é bastante heterogênea, variando em função de especificidades setoriais, territoriais e em razão da própria trajetória evolutiva dos mesmos, a partir da qual laços de cooperação podem ser reforçados. Reconhecer esta heterogeneidade é importante, mas isto não implica desconhecer o fato de que existe um movimento conjunto de construção de competências no âmbito daqueles arranjos, que pode determinar, ou não, uma progressiva equalização dos níveis de eficiência dos agentes a ele integrados. Nesse sentido, é possível supor que a manifestação dos efeitos mencionados está diretamente articulada à consolidação de um determinado "núcleo dinâmico", formado por um conjunto de empresas com patamares superiores de capacitação, aprendizado e desempenho inovativo. Assume-se, portanto, que as empresas integradas a esse núcleo apresentam maior capacidade potencial de indução do aprendizado interativo por meio de relacionamentos interindustriais, os quais geram importantes efeitos spillovers que possibilitam a sustentabilidade do dinamismo do arranjo como um todo.

É possível destacar, com base em insights da literatura de tradição evolucionária, alguns elementos associados à "dinâmica interna" dos arranjos produtivos locais em relação aos quais aquele núcleo desempenharia um papel fundamental. Em primeiro lugar, em função da maior densidade potencial de seus relacionamentos, é provável que aquele núcleo desempenhe um papel fundamental na "codificação" de conhecimentos associados aos "fluxos informacionais" que conectam os diversos agentes integrados aos arranjos. Em segundo lugar, é possível considerar a existência de um processo de "difusão concêntrica" de inovações, na linha de argumentação desenvolvida por Bidault (1993). Essa "difusão concêntrica" estaria associada a uma lógica sequencial, através da qual uma inovação gerada por um agente integrado ao núcleo dinâmico do arranjo tende a difundir-se inicialmente para aqueles que fazem parte de sua "rede direta" de relacionamentos locais e, a partir daí, para aqueles inseridos em "redes indiretas" e, finalmente, para o mercado. Por fim, tal núcleo está associado à consolidação de uma determinada "capacidade de atração" para o arranjo, na medida em que proporciona a geração de efeitos spillovers que retroalimentam a competitividade das empresas integradas ao arranjo.

A trajetória evolutiva gerada a partir da consolidação desse núcleo não implica, porém, necessariamente o fortalecimento de vínculos cooperativos duradouros entre agentes no interior do arranjo. Nesse sentido, há indícios de que, em virtude da intensidade das pressões competitivas, é comum que determinados agentes optem pela adoção de estratégias de adaptação que podem resultar no arrefecimento de 
práticas cooperativas, gerando importantes desdobramentos sobre a conformação e estratégia evolutiva do arranjo. Em particular, é possível que algumas das firmas mais dinâmicas e inovadoras venham a reduzir a intensidade de suas relações internas no âmbito do arranjo, em função daquelas pressões. Evidências levantadas por uma vasta literatura sobre "distritos italianos", por exemplo, demonstram que essas trajetórias variam consideravelmente de caso para caso (WHITFORD, 2001), e que, mesmo no âmbito de um único "distrito" isolado para fins analíticos, tais trajetórias raramente podem ser caracterizadas como "lineares", podendo resultar em períodos de intensificação ou arrefecimento da cooperação. Em termos metodológicos, essa constatação traz implicações importantes acerca do recorte analítico mais adequado para avaliação daquelas trajetórias - podendo-se contrapor um recorte baseado em "sistemas (ou grupos) de firmas" a outro que privilegia a análise de "firmas no sistema”.

Reconhecendo-se a complexidade dessa dinâmica e atentando-se para a dificuldade de caracterização de trajetórias "lineares" a partir da mesma, sugere-se que a noção de "núcleo dinâmico" constitui um recorte analítico que pode contribuir para superar a aparente dicotomia entre análises que privilegiam "sistemas de firmas" ou a ação individualizada de "firmas no sistema", refletindo também uma opção metodológica que busca caracterizar a dinâmica inovativa a partir de uma concepção sistêmica do processo de inovação. Assim, ao se considerar como categoria-chave da análise a presença daquele "núcleo dinâmico", sugere-se que as mesmas apresentam uma maior capacidade potencial de indução do aprendizado interativo por meio de relacionamentos interindustriais, influenciando decisivamente a dinâmica inovativa e a trajetória evolutiva do arranjo. Assim, o trabalho procura explorar o potencial de determinadas técnicas que possibilitam um tratamento analítico mais rigoroso dos processos de interação, aprendizado e capacitação que ocorrem em escala local com base em estímulos gerados a partir daquele núcleo. No entanto, a possibilidade de esse núcleo comandar um processo a partir do qual seria gerada uma dinâmica "virtuosa" de fortalecimento da cooperação demandaria a incorporação de outros aspectos, que fogem ao escopo deste trabalho e constituem campos de investigação possíveis de serem explorados - com o auxílio daquele instrumento analítico - em uma agenda de pesquisa futura, dentre os quais, é possível mencionar: (i) o desenvolvimento de uma análise intertemporal que possibilite avançar na caracterização da trajetória evolutiva do arranjo; (ii) a incorporação dos impactos que as pressões competitivas e os "regimes tecnológicos setoriais" (MALERBA, 2004) exercem sobre as estratégias dos agentes e, consequentemente, sobre aquela trajetória; (iii) um maior detalhamento das idiossincrasias relativas ao porte, níveis de capacitação e estratégias dos diversos agentes integrados ao arranjo. 
O papel de difusor de tecnologias para os demais setores industriais confere às indústrias eletrometal-mecânicas ${ }^{5}$ uma posição estratégica nas trajetórias de crescimento dos países. No desenvolvimento econômico do Estado de Santa Catarina, as indústrias eletrometal-mecânicas tiveram papel de destaque no contexto de uma estrutura produtiva bastante diversificada. Uma característica importante do processo de industrialização catarinense foi a concentração industrial em determinados espaços do território, criando áreas de especializações produtivas. As atividades relacionadas a essas indústrias são responsáveis por aproximadamente $25 \%$ do valor da transformação industrial catarinense, e a microrregião de Joinville apresenta os índices mais elevados de especialização ${ }^{6}$ do Estado.

A industrialização na microrregião de Joinville foi marcada, no seu início, pela criação de empresas correspondentes às indústrias da primeira etapa da industrialização por substituição de importações tais como têxtil e alimentos, e também pela presença de empresas das indústrias eletrometal-mecânicas que atendiam, sobretudo, ao mercado local, e posteriormente expandiram a sua capacidade produtiva e se consolidaram no mercado nacional. A partir da década de 70, as grandes empresas ingressaram no mercado internacional, destinando suas exportações principalmente para a América Latina e EUA. Com o amadurecimento de sua estrutura industrial, a microrregião passou a ser reconhecida nacional e internacionalmente por sua forte tradição industrial, mais especificamente em relação à eletrometal-mecânica e à indústria têxtil. Na microrregião, cerca de $30 \%$ da mão-de-obra está alocada na eletrometal-mecânica, com a participação de uma ampla gama de empresas dos mais diversos portes. Essa forte participação no emprego ganha ainda mais destaque considerando-se a diversificação da estrutura produtiva local com forte presença de outras indústrias como a têxtil, a alimentícia, a de materiais plásticos, entre outras.

5 Para a definição das indústrias eletrometal-mecânicas adota-se neste trabalho a classificação do CNAE IBGE: a Indústria Metalúrgica (inclui as divisões: Metalurgia básica; Fabricação de produtos de metal exclusive máquinas e equipamentos; e Reciclagem); a Indústria Mecânica (inclui as divisões: Fabricação de máquinas e equipamentos; Fabricação de máquinas para escritório e equipamentos de informática; e Fabricação de equipamentos de instrumentação médico-hopitalares, instrumentos de precisão e ópticos, equipamentos para automação industrial, cronômetros e relógios); a Indústria de Material Elétrico e de Comunicação (inclui as divisões: Fabricação de máquinas, aparelhos e materiais elétricos; e Fabricação de material eletrônico e de aparelhos e equipamentos de comunicaçóes); e a Indústria de Material de Transporte (inclui as divisões: Fabricação e montagem de veículos automotores, reboques e carrocerias; e Fabricação de outros equipamentos de transporte).

6 O Quociente Locacional (QL) nos dá uma noção comparativa da especialização da microrregião em função do país. Em casos em que o QL é superior a l, a especialização da microrregião nessa atividade é superior à especialização do Brasil (BRITTO; ALBUQUERQUE, 2002). Para a microrregião de Joinville, os QLs dos segmentos de atividades relacionadas à indústria eletrometal-mecânica são: Metalurgia 4,27; Mecânica 7,04; Material Elétrico e de Comunicação 5,77; e Material de Transporte 2,35. 
A microrregião de Joinville está localizada no nordeste do Estado de Santa Catarina, sendo vizinha de duas áreas com grande concentração industrial, a microrregião de Blumenau, também em Santa Catarina, e a região metropolitana de Curitiba, no Paraná. ${ }^{7}$ Tal proximidade geográfica impulsionou o desenvolvimento das indústrias eletrometal-mecânicas na microrregião, uma vez que grande parte da produção "tinha e ainda tem" como destino esses dois mercados. O arranjo possui uma densa estrutura produtiva local e grande heterogeneidade no tamanho das empresas, observando-se especializações por tamanho de empresas dentro dos diversos grupos de atividades. As características da estrutura produtiva local relacionadas ao porte e atividades dos estabelecimentos são mostradas na Tabela 1.

As informações utilizadas no estudo foram obtidas em pesquisa de campo numa amostra estratificada de 83 empresas ${ }^{8}$ localizadas nos municípios de Joinville e Jaraguá do Sul. A análise das informações coletadas junto a empresas do arranjo eletrometal-mecânico indica uma intrincada estrutura de relacionamentos internos, a qual constitui evidência da complexa dinâmica interna de operação desse arranjo, no tocante à criação de estímulos ao aprofundamento de mecanismos interativos de aprendizado capazes de reforçar a capacitação dos agentes locais. Há também indícios de que diferentes formas de ações cooperativas estão presentes no arranjo, particularmente envolvendo relacionamentos verticais entre clientes e fornecedores integrados a redes de subcontratação.

7 Os dados relacionados à importância do comércio, para as empresas do arranjo, com essas duas regióes são apresentados em Stallivieri (2004).

8 A estratificação da amostra adota os critérios de proporcionalidade relacionados ao porte e aos segmentos de atuação dos estabelecimentos, seguindo a aleatoriedade na seleção das empresas que foram entrevistadas em cada estrato da amostra. 
TABELA I - NÚMERO DE ESTABELECIMENTOS E PARTICIPAÇÃO NO TOTAL DE EMPRESAS DO ARRANJO ELETROMETAL-MECÂNICO DE JOINVILLE POR SEGMENTO DE ATIVIDADE ECONÔMICA EM 2002

\begin{tabular}{|c|c|c|c|c|c|c|c|c|c|c|}
\hline \multirow{3}{*}{ Segmentos } & \multicolumn{10}{|c|}{ Tamanho do Estabelecimento } \\
\hline & \multicolumn{2}{|c|}{ Micro } & \multicolumn{2}{|c|}{ Pequeno } & \multicolumn{2}{|c|}{ Média } & \multicolumn{2}{|c|}{ Grande } & \multicolumn{2}{|c|}{ Total } \\
\hline & Número & $\%$ & Número & $\%$ & Número & $\%$ & Número & $\%$ & Número & $\%$ \\
\hline Metalurgia Básica & 58 & 6,9 & 21 & 2,5 & 8 & 0,9 & 2 & 0,2 & 89 & 10,6 \\
\hline Fabricação de produtos de Metal - Exclusive Máquinas e Equipamentos & 369 & 44,1 & 44 & 5,2 & 4 & 0,4 & 2 & 0,2 & 419 & 50,1 \\
\hline Fabricação de Máquinas e Equipamentos & 169 & 20,2 & 46 & 5,5 & 6 & 0,7 & 4 & 0,4 & 225 & 26,9 \\
\hline Fabricação de Máquinas para Escritório e Equipamentos de Informática & 1 & 0,1 & 0 & 0 & 0 & 0 & 0 & 0 & 1 & 0,1 \\
\hline Fabricação de Máquinas, Aparelhos e Materiais Elétricos & 31 & 3,1 & 9 & 1 & 2 & 0,2 & 4 & 0,4 & 46 & 5,5 \\
\hline $\begin{array}{l}\text { Fabricação de Equipamentos de Instrumentação médico-hospitalares, Instrumentos } \\
\text { de Precisão e Ópticos, Equipamentos para a Automação Industrial, Cronômetros e } \\
\text { Relógios }\end{array}$ & 15 & 1,7 & 2 & 0,2 & 2 & 0,2 & 0 & 0 & 19 & 2,2 \\
\hline Fabricação e Montagem de Veículos Automotores, Reboques e Carrocerias & 28 & 3,3 & 6 & 0,7 & 1 & 0,1 & 1 & 0,1 & 36 & 4,3 \\
\hline TOTAL & 671 & 80,3 & 128 & 15,3 & 23 & 2,7 & 13 & 1,5 & 835 & 100 \\
\hline
\end{tabular}

Fonte: MTe /RAIS - 2002.

Elaboração própria. 
Cabe salientar que a análise está baseada em uma autoavaliação das próprias empresas investigadas acerca dos principais fatores que influenciam seus esforços de aprendizado e o processo de capacitação resultante. Esse mesmo tipo de procedimento foi adotado para avaliar os resultados desses esforços, bem como os impactos percebidos pelos agentes em termos do processo de capacitação. Embora se reconheça que tal tipo de coleta de informaçóes possa distorcer os resultados, pois nem sempre o próprio entrevistado possui o melhor entendimento do que se pergunta, o procedimento é amplamente reconhecido como pertinente na realização de análises que abordam o processo de construção de capacitações inovativas. Tal procedimento foi, inclusive, mencionado como um instrumento importante pelo Mamual de Oslo (2005) da OCDE, o qual estabelece princípios metodológicos que têm orientado a realização de Innovation Suveys em diversos países. Além disso, a obtenção de informações a partir de uma amostra estratificada de 83 empresas localizadas nos municípios de Joinville e Jaraguá do Sul tende a minimizar problemas ligados à diversidade de interpretação das questões entre os agentes.

A análise aqui desenvolvida é uma tentativa de avançar no tratamento analítico de arranjos produtivos locais procurando mensurar as formas de interação nos processos de cooperação e de aprendizado no arranjo pelo agrupamento das informações coletadas em indicadores. É, portanto, de natureza "exploratória”, baseando-se na seleção de um conjunto de indicadores que possibilitam captar elementos importantes da "dinâmica" dos processos de cooperação e aprendizado. Procurou-se utilizar um conjunto selecionado de perguntas transformando atributos qualitativos, tais como a importância atribuída pela empresa a determinado evento, em quantitativos, ou seja, encontrando um valor entre 0 e 1 que expressasse a opinião da empresa sobre cada evento. Foi criado um conjunto de 24 indicadores (apresentados no Anexo 1 deste trabalho) que contemplam quatro aspectos principais relacionados à construção de capacitações locais: i) esforço tecnológico; ii) aprendizagem tecnológica; iii) ações cooperativas; iv) desempenho inovativo.

A conjugação dos indicadores selecionados possibilitou a obtenção de evidências sobre o grau de articulação das firmas entre si e, portanto, da eficiência coletiva do arranjo. Adicionalmente, foi possível fazer uma tipificação dos agentes constituintes do arranjo, de modo a identificar aqueles que se integram ao seu "núcleo dinâmico". Para atingir esse objetivo foram utilizados alguns procedimentos estatísticos. 
FIGURA I - MÉDIA DOS INDICADORES PARA CADA CLUSTER DE EMPRESAS DA AMOSTRA DO ARRANJO ELETROMETAL-MECÂNICO DA MICRORREGIATO DE JOINVILLE/SC

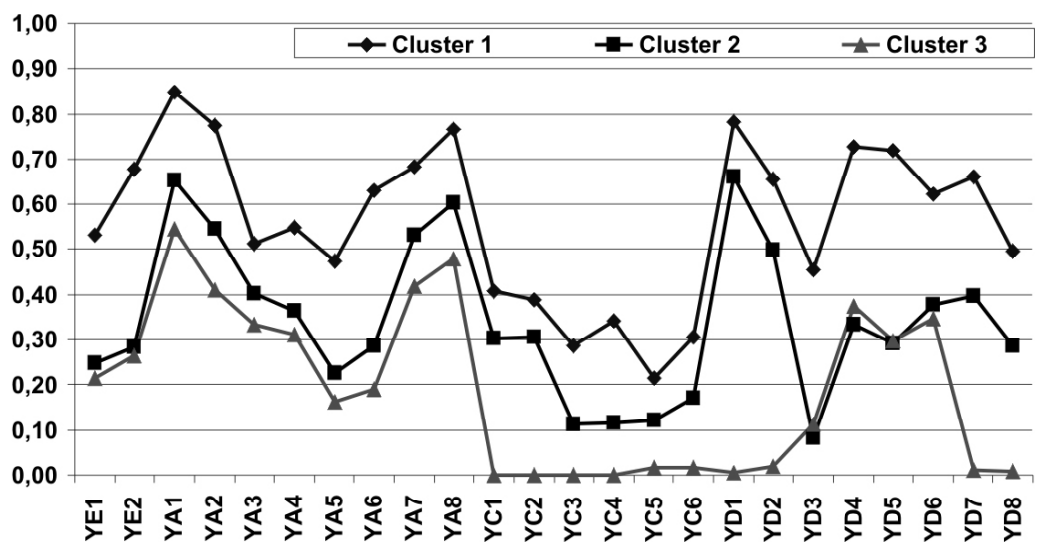

Fonte: Pesquisa de campo (2003). Elaboração própria com base no Software STATISTICA 6.0.

Inicialmente, foi feita a análise de agrupamento (cluster) tanto pelo método hierárquico quanto pelo não-hierárquico. Após a identificação dos clusters aplicou-se a análise fatorial nos indicadores referentes ao esforço tecnológico e ao desempenho das empresas, para caracterizar graficamente o comportamento das empresas que integram os diferentes clusters identificados.

\section{APLICAÇÃO DAS TÉCNICAS DE ANÁLISE MULTIVARIADA}

A análise multivariada consiste num conjunto de técnicas exploratórias de dados que, através de elementos gráficos e/ou de caracterização dos dados, permite identificar certos padrões no comportamento dos mesmos. A análise de cluster avalia um conjunto de relações interdependentes entre os casos sem fazer distinção entre variáveis dependentes e independentes. Ela permite classificar objetos, no caso empresas, em grupos relativamente homogêneos, com base no conjunto de indicadores considerados (MALHOTRA, 2001). Pela análise de cluster, ${ }^{9}$ utilizando todos os 24 indicadores, foram identificados os distintos agrupamentos de empresas (clusters) com características similares nos indicadores.

Num primeiro momento, utilizou-se um método de agrupamentos não-hierárquicos, o método K-médias. O método indicou a existência de três clusters de empresas a

9 Para a formalização matemática e estatística da análise de cluster, ver Johnson e Wichern (1998), Bouroche e Saporta (1980), Banet e Morineau (1999), Malhotra (2001). 
partir da utilização do conjunto de indicadores propostos. A Figura 1 ressalta a média dos indicadores para cada agrupamento e pode-se verificar que existem diferenças entre os clusters $^{10}$ expressas pelas médias significativamente distintas dos indicadores.

Num segundo momento, visando confirmar os resultados obtidos com o método de $K$-médias valeu-se do método hierárquico (aglomerativos) de agrupamento, o método Joining ${ }^{11}$, selecionando-se as opções referentes a ligações completas, que avalia a distância entre os "vizinhos" mais distantes de dois agrupamentos distintos, utilizando-se como medida de distância o quadrado da distância Euclidiana. Os resultados alcançados estão presentes na Figura 2, que mostra o dendograma ${ }^{12}$ dos agrupamentos de empresas.

\section{FIGURA 2 - DENDOGR AMA, ÁRVORE DE AGRUPAMENTO DAS EMPRE- SAS DO ARRANJO ELETROMETAL-MECANICO DA MICROR- REGIATO DE JOINVILLE/SC}

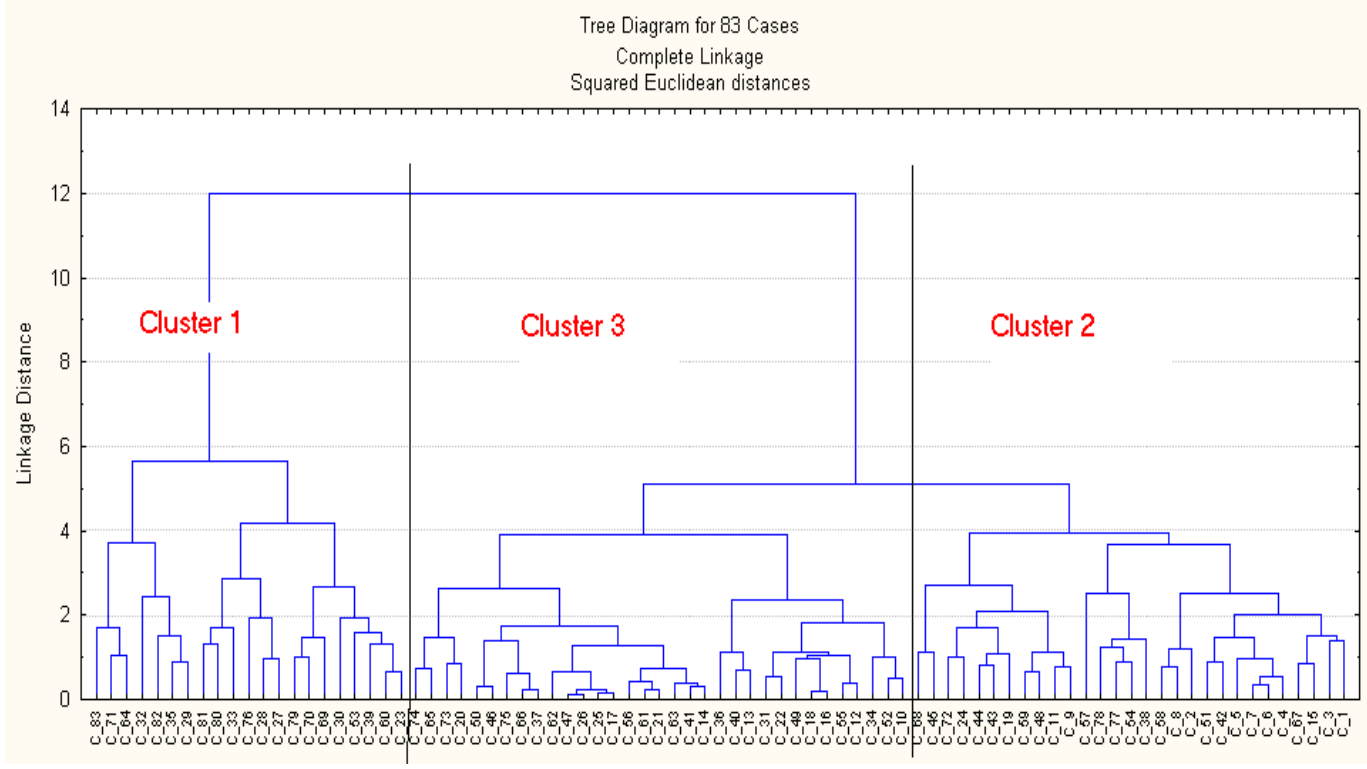

Fonte: Pesquisa de campo (2003). Elaboração própria com base no Software STATISTICA 6.0.

Cabe frisar que os resultados obtidos com tal método são idênticos aos obtidos com o método anterior, uma vez que as empresas classificadas no cluster 1, por exemplo,

10 A tabela que contém a média dos indicadores para cada cluster e o teste de significância dos mesmos é exibida no Anexo 2.

11 Disponível no STATISTICA 6.0.

12 "Árvore de agrupamentos". 
através do método de K-médias, são as mesmas identificadas no primeiro agrupamento através do método Joining. Portanto, os dois métodos de agrupamentos utilizados apresentam o mesmo resultado.

Posteriormente, com o intuito de identificar o comportamento relacionado ao esforço tecnológico e ao desempenho das empresas que integram cada cluster, aplicou-se a análise fatorial ${ }^{13}$ por meio do método de varimax normalized ${ }^{14}$ para os indicadores relacionados a essas dimensões. ${ }^{15} \mathrm{O}$ principal propósito da análise fatorial é descrever, se possível, as relações de covariâncias entre muitas variáveis por poucos fatores subjacentes, mas não-observáveis. Por conseguinte, a aplicação da análise fatorial possibilitará identificar os principais fatores e o peso das variáveis para cada fator, bem como caracterizar o comportamento das empresas (dos casos) em relação a esses fatores.

Parte-se da identificação dos principais fatores que explicam a variância entre agentes, com base nos indicadores selecionados. A Tabela 2 apresenta os autovalores relacionados a cada fator e a porcentagem da variação dos dados explicada. Para este trabalho, optou-se por selecionar quatro fatores, que em conjunto explicam 69,01\% das variações dos dados. Nota-se que os fatores 1 e 2 possuem os mais elevados autovalores, assim como explicam a maior porcentagem da variância dos dados.

13 Para a formalização matemática e estatística da análise fatorial, ver Johnson e Wichern (1998), Bouroche e Saporta (1980), Banet e Morineau (1999), Malhotra (2001).

14 Utilizando-se do método do componente principal, poderíamos chegar a resultados semelhantes. Todavia, o método utilizado é mais refinado, visto que promove a rotaçẫo ortogonal dos eixos relacionados aos fatores e às variáveis, com o intuito de chegar ao melhor resultado possível.

15 Como destacado, nesta altura do trabalho utilizam-se os 10 indicadores relacionados ao esforço tecnológico, ao desempenho referente aos processos de aprendizagem e cooperação e ao desempenho inovativo. A redução do número de indicadores (variáveis) utilizados para a análise proporciona melhor visualização dos fatores identificados, pois nesta altura da análise a utilização de todos os indicadores propostos reduziria significativamente a porcentagem da variância explicada pelos fatores. Foram então selecionados os indicadores que potencialmente levem a uma diferenciação melhor entre as empresas da amostra. 
TABELA 2 - AUTOVALORES E VARIÂNCIA RELACIONADA AOS FATORES SELECIONADOS

\begin{tabular}{ccccc}
\hline Fator & Autovalor & $\begin{array}{c}\text { \% da variância } \\
\text { total explicada }\end{array}$ & Autovalor acumulado & $\begin{array}{c}\text { \% da variância } \\
\text { acumulada explicada }\end{array}$ \\
\hline 1 & 4,5070 & 45,0699 & 4,5070 & 45,0699 \\
2 & 1,7213 & 17,2132 & 6,2283 & 62,2831 \\
3 & 0,2843 & 2,8431 & 6,5126 & 65,1262 \\
4 & 0,3893 & 3,8934 & 6,9020 & 69,0196 \\
\hline
\end{tabular}

Fonte: Pesquisa de campo (2003.). Elaboração própria com base no Software STATISTICA 6.0.

A Tabela 3 exibe a frequência acumulada de explicação da variância de cada indicador (variável) pelo total de fatores selecionados. Em relação a esse ponto, observa-se que os indicadores YD1, YD2, YD7 e YD8 possuem a maior parte de sua variância explicada apenas com um fator. Os indicadores YD6 e YD5 têm a maior parte de suas variâncias explicadas com dois fatores e os indicadores YEl, YE2, YD3 e YD4, com a utilização de quatro fatores. Logo, constata-se que a análise baseada em apenas um fator é suficiente para explicar a variância dos indicadores YDl, YD2, YD7 e YD8; porém, essa não explica a variância dos demais indicadores, e atinge-se uma porcentagem de explicação razoável da variância dos demais com a utilização de quatro fatores.

\section{TABELA 3 - VARIÂNCIAS ACUMULADAS DOS INDICADORES EXPLICA- DAS PELOS FATORES SUBJACENTES ANALISADOS}

\begin{tabular}{|c|c|c|c|c|c|}
\hline Indicadores / Variáveis & Com 1 Fator & Com 2 Fatores & Com 3 Fatores & m 4 Fator & -Quadrado \\
\hline $\begin{array}{l}\text { YE2 - Constância do desenvolvimento de atividades } \\
\text { inovativas }\end{array}$ & 0,0530 & 0,3867 & 0,3894 & 0,7633 & 0,6647 \\
\hline YE1 - Treinamento e capacitação de RH & 0,1145 & 0,2262 & 0,2275 & 0,5218 & 0,4775 \\
\hline YD6 - Impacto gerado pela introdução de inovações & 0,0552 & 0,4624 & 0,4726 & 0,5931 & 0,5386 \\
\hline $\begin{array}{l}\text { YD3 - Introdução de novos produtos para o mercado } \\
\text { internacional e / ou novos processos para o setor } \\
\text { de atuação }\end{array}$ & 0,0118 & 0,0275 & 0,0283 & 0,3709 & 0,2763 \\
\hline $\begin{array}{l}\text { YD4 - Introdução ou melhorias de novos produtos e / ou } \\
\text { processos para a empresa }\end{array}$ & 0,0032 & 0,1918 & 0,2358 & 0,5234 & 0,4655 \\
\hline YD5 - Introdução de inovações organizacionais & 0,0241 & 0,7134 & 0,7135 & 0,7541 & 0,5185 \\
\hline YD1 - Melhora em produtos e processos & 0,8356 & 0,8557 & 0,8583 & 0,8836 & 0,7738 \\
\hline $\begin{array}{l}\text { YD2 - Melhora nas capacidades administrativas e } \\
\text { mercadológicas }\end{array}$ & 0,7187 & 0,7576 & 0,7593 & 0,7662 & 0,7194 \\
\hline $\begin{array}{l}\text { YD7 - Melhora nas capacidades produtivas e } \\
\text { organizacionais derivadas dos processos de } \\
\text { cooperação }\end{array}$ & 0,7160 & 0,7381 & 0,7577 & 0,8342 & 0,7916 \\
\hline $\begin{array}{l}\text { YD8 - Melhora nas capacidades administrativas e } \\
\text { mercadológicas derivadas dos processos de } \\
\text { cooperação }\end{array}$ & 0,5156 & 0,5490 & 0,8559 & 0,8915 & 0,6367 \\
\hline
\end{tabular}

Fonte: Pesquisa de campo (2003). Elaboração própria com base no Software STATISTICA 6.0. 
Após a identificação dos autovalores associados a cada fator e da variância dos indicadores explicada pelos fatores, parte-se para a análise de cada fator utilizado com o intuito da caracterização destes. A Tabela 4 mostra a "carga fatorial ${ }^{16 "}$ de cada indicador utilizado para os fatores. Quanto ao fator 1 , verifica-se que os indicadores YDl, YD2, YD7 e YD8 possuem um peso maior na explicação deste. No fator 2, os indicadores YE2, YD6 e YD5 são mais relevantes, sendo mais influentes no comportamento deste fator. No que diz respeito ao fator 3, nota-se que os indicadores em questão possuem baixa influência neste, e o único que possui um peso significante é o indicador YD8. Para o fator 4, os indicadores YE2, YE1, YD3 e YD4 influenciam com maior intensidade este fator, possuindo maior peso na determinação do seu comportamento.

\section{TABELA 4 - CARGA FATORIAL DOS INDICADORES UTILIZADOS NOS FATORES SUBJACENTES}

\begin{tabular}{|c|c|c|c|c|}
\hline Indicadores & Fator 1 & Fator 2 & Fator 3 & Fator 4 \\
\hline YE2 - Constância do desenvolvimento de atividades inovativas & 0,2303 & 0,5776 & 0,0518 & 0,6115 \\
\hline YE1 - Treinamento e capacitação de RH & 0,3383 & 0,3343 & $-0,0357$ & 0,5425 \\
\hline YD6 - Impacto gerado pela introdução de inovações & 0,2350 & 0,6381 & 0,1011 & 0,3470 \\
\hline $\begin{array}{l}\text { YD3 - Introdução de novos produtos para o mercado internacional e / } \\
\text { ou novos processos para o setor de atuação }\end{array}$ & 0,1087 & 0,1250 & 0,0289 & 0,5853 \\
\hline $\begin{array}{l}\text { YD4 - Introdução ou melhorias de novos produtos e / ou processos } \\
\text { para a empresa }\end{array}$ & 0,0569 & 0,4342 & 0,2097 & 0,5363 \\
\hline YD5 - Introdução de inovações organizacionais & 0,1553 & 0,8303 & 0,0064 & 0,2016 \\
\hline YD1 - Melhora em produtos e processos & 0,9141 & 0,1417 & $-0,0514$ & 0,1591 \\
\hline YD2 - Melhora nas capacidades administrativas e mercadológicas & 0,8477 & 0,1974 & 0,0401 & 0,0831 \\
\hline $\begin{array}{l}\text { YD7 - Melhora nas capacidades produtivas e organizacionais deri- } \\
\text { vadas dos processos de cooperação }\end{array}$ & 0,8462 & 0,1484 & 0,1401 & 0,2766 \\
\hline $\begin{array}{l}\text { YD8 - Melhora nas capacidades administrativas e mercadológicas } \\
\text { derivadas dos processos de cooperação }\end{array}$ & 0,7180 & 0,1829 & 0,5539 & 0,1888 \\
\hline
\end{tabular}

Fonte: Pesquisa de campo (2003). Elaboração própria com base no Software STATISTICA 6.0.

Portanto, no que tange aos fatores subjacentes à análise, estes poderiam ser formalizados da seguinte forma:

Fator 1 = 0,23YE2+0,33YE1+0,23YD6+0,10YD3+0,05YD4+0,15YD5+ $\underline{0,91 Y D 1+}$ $+\underline{0,84 \mathrm{YD} 2}+\underline{0,84 \mathrm{YD} 7}+\underline{0,71 \mathrm{YD} 8}$

Fator $2=\underline{0,57 \mathrm{YE} 2}+0,33 \mathrm{YE} 1+\underline{0,63 \mathrm{YD} 6}+0,12 \mathrm{YD} 3+0,43 \mathrm{YD} 4+\underline{0,83 \mathrm{YD} 5}+0,14 \mathrm{YD} 1+$ $+0,19$ YD2+0,14YD7+0,18YD8

16 O peso de cada indicador para os fatores. 
Fator $3=0,05 \mathrm{YE} 2-0,03 \mathrm{YE} 1+0,10 \mathrm{YD} 6+0,02 \mathrm{YD} 3+0,20 \mathrm{YD} 4+0,006 \mathrm{YD} 5-0,05 \mathrm{YD} 1+$ $+0,04 \mathrm{YD} 2+0,14 \mathrm{YD} 7+\underline{0,55 \mathrm{YD} 8}$

Fator $4=\underline{0,61 \mathrm{YE} 2}+\underline{0,54 \mathrm{YE} 1}+0,34 \mathrm{YD} 6+\underline{0,58 \mathrm{YD} 3}+\underline{0,53 \mathrm{YD}} 4+0,20 \mathrm{YD} 5+0,15 \mathrm{YD} 1+$ $+0,08 \mathrm{YD} 2+0,27 \mathrm{YD} 7+0,18 \mathrm{YD} 8$.

Logo, mediante a análise da variância acumulada explicada pelos fatores e da carga fatorial de cada indicador, podemos caracterizar os fatores identificados. O fator 1 está relacionado a melhorias em produtos e processos em função dos processos de aprendizagem (YDl), a melhoras nas capacidades administrativas e mercadológicas em função dos processos de aprendizagem (YD2), a melhoras nas capacidades produtivas e organizacionais derivadas dos processos de cooperação (YD7) e a melhoras nas capacidades administrativas e mercadológicas derivadas dos processos de cooperação (YD8); assim, este primeiro fator representa tais indicadores. Para a análise das empresas da amostra, quanto mais elevado for o fator 1 , mais elevados tendem a ser estes indicadores.

O fator 2 está ligado ao impacto gerado pela introdução de inovações (YD6) e à introdução de inovações organizacionais (YD5); então, para as empresas da amostra, quanto mais elevado for este fator, maiores são os referidos indicadores. $\mathrm{O}$ fator 3 possui, em geral, uma baixa carga fatorial dos indicadores utilizados; este explica com baixa intensidade os indicadores, com destaque apenas para melhoras nas capacidades administrativas e mercadológicas derivadas dos processos de cooperação (YD8).

Por fim, o fator 4 é explicado e possui um maior peso nos indicadores relacionados à constância no desenvolvimento das atividades inovativas (YE2), ao esforço de treinamento e capacitação de recursos humanos (YEl), à introdução de novos produtos para o mercado internacional e/ou novos processos para o setor de atuação (YD3) e à introdução ou melhorias de produtos e processos novos para as empresas (YD4). Logo, de forma resumida, podemos concluir que o fator 1 está associado aos resultados obtidos com os processos de aprendizagem e cooperação pelas firmas da amostra; o fator 2, ao impacto gerado pela introdução de inovações e introdução de inovações organizacionais pelas empresas; o fator 3, principalmente ao impacto administrativo e mercadológico gerado pelos processos de cooperação; e o fator 4, à introdução de inovações "radicais ${ }^{17}$ ", à introdução de inovações imitativas, ao esforço

17 O conceito de inovações "radicais" deve ser considerado no contexto particular da análise, estando relacionado à tentativa de distinguir diferentes padrốes de conduta quanto à introdução de inovações por parte das empresas investigadas. Trata-se, na verdade, de inovaçốes associadas ao desenvolvimento e introdução de novos produtos no mercado que, na visão das empresas, constituem uma "novidade" efetiva em relação ao seu setor de atuação no país e/ou em relação ao mercado internacional (obviamente, neste último caso, considerando as informações que as empresas têm disponíveis acerca do comportamento desse mercado). Assim, o conceito de inovações "radicais" não deve ser associado à fronteira de 
de capacitação e treinamento de $\mathrm{RH}$ e ao desenvolvimento de atividades inovativas pelas empresas da amostra.

Com base nos fatores descritos, é possível analisar as características das empresas ${ }^{18}$ da amostra. A Figura 3 apresenta as características das empresas para os fatores 1 , 2 e 3. Pode-se perceber que, a partir da análise destes fatores, fica clara a divisão das empresas da amostra em dois grupos (clusters) com características distintas. As empresas do cluster 3 exibem os valores mais reduzidos em relação ao fator 1 , o que significa que os resultados obtidos por essas empresas com os processos de aprendizagem e cooperação são baixos, ou praticamente insignificantes.

\section{FIGURA 3 - PLOTAGEM 3D DOS FATORES 1, 2 E 3 PARA AS EMPRESAS DA AMOSTR A DO ARR ANJO ELETROMETAL-MECÂNICO DA MICRORREGIÃO DE JOINVILLE/SC}

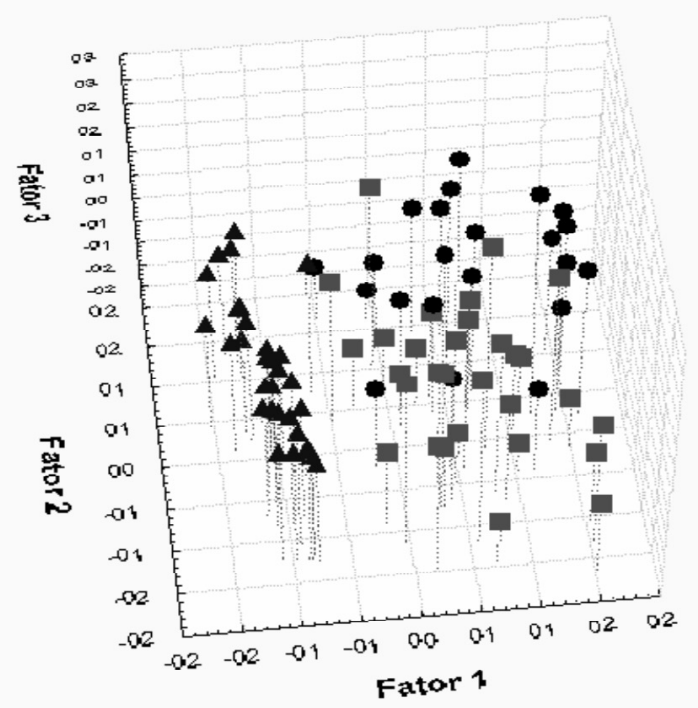

- Cluster 1

4 Cluster 3

Fonte: Pesquisa de campo (2003). Elaboração própria com base no Software STATISTICA 6.0.

uma trajetória tecnológica setorial claramente definida e sim à percepção, intrinsecamente subjetiva, das empresas acerca do grau de "novidade" incorporada aos produtos comercializados. Cabe ressaltar que, embora se reconheça a subjetividade inerente a esse tipo de avaliação, tal procedimento metodológico é compatível com os procedimentos de avaliação do desempenho inovativo propostos pelo Mamual de Oslo (2005) da OCDE, sendo amplamente utilizado em Innovation Suveys realizadas por diferentes países, inclusive no caso da PINTEC (2005) brasileira. De forma a ressaltar esse aspecto, optou-se pela utilização de "aspas" ao caracterizar-se tais informações como "radicais", visando diferenciá-las em relação a outras inovações que, na avaliação das empresas, incorporam um menor grau de "novidade" notadamente inovações de processo que já são comumente utilizadas por outras empresas atuantes no mercado.

18 Optou-se, neste ponto, por uma análise gráfica, uma vez que uma análise matemática criaria 83 equaçốes (uma para cada empresa da amostra) refletindo o peso de cada fator para cada empresa. 
Verifica-se que as empresas pertencentes aos clusters 1 e 2 obtêm resultados semelhantes e mais elevados nos processos de cooperação e aprendizagem, assim como, de modo geral, introduzem com mais intensidade inovações organizacionais, como também a introdução de inovações gera um impacto mais intenso nessas empresas. Portanto, a análise gráfica dos fatores 1,2 e 3 permite identificar fortes diferenças entre as empresas do cluster 3 e as dos clusters 1 e 2 ; todavia, podemos observar que não existem diferenças significativas entre as empresas dos clusters 1 e 2 quanto aos resultados obtidos com os processos de aprendizagem e cooperação, nem em relação à introdução de inovações organizacionais e aos impactos gerados pela introdução de inovações.

A Figura 4 aponta as características das empresas da amostra no que diz respeito aos fatores 1,2 e 4. Com essa análise, podemos concluir que existem diferenças significativas entre as empresas dos clusters 1 e 2 , e que consistem, sobretudo, na introdução de inovações radicais, de inovações imitativas e nos esforços de treinamento e capacitação de recursos humanos e de desenvolvimento de atividades inovativas (fator 4). As empresas do cluster 1 apresentam os maiores valores relacionados ao fator 4, o que significa que elas introduzem com maior intensidade inovaçóes referentes a produtos e processos (inclusive para o mercado internacional) e são mais intensivas nos processos de treinamento e capacitação de recursos humanos e de desenvolvimento de atividades inovativas. Desse modo, a principal diferença das empresas dos agrupamentos 1 e 2 , nos indicadores utilizados na análise fatorial, consiste na introdução de inovaçóes, com uma taxa maior nas empresas do cluster 1.

A análise fatorial desenvolvida permitiu identificar as peculiaridades de cada fator e, posteriormente, os distintos comportamentos das empresas da amostra, em função dos indicadores utilizados nesta etapa do trabalho. Observa-se que a principal diferença quanto ao comportamento das empresas está na introdução de inovações "radicais" e imitativas, no desenvolvimento de atividades inovativas e de treinamento e capacitação de $\mathrm{RH}$, materializado numa maior discrepância entre as empresas que integram os clusters nos valores referentes ao fator 4 . Portanto, podemos concluir que as empresas inseridas no cluster 1 introduzem mais inovações produtivas e são mais intensivas nos processos de treinamento e capacitação de RH e de desenvolvimento de atividades inovativas, pois, de modo geral, elas mostram os mais elevados valores referentes ao quarto fator subjacente. 
FIGURA 4 - PLOTAGEM 3D DOS FATORES 1, 2 E 4 PARA AS EMPRESAS DA AMOSTR A DO ARRANJO ELETROMETAL-MECANICO DA MICRORREGIATO DE JOINVILLE/SC

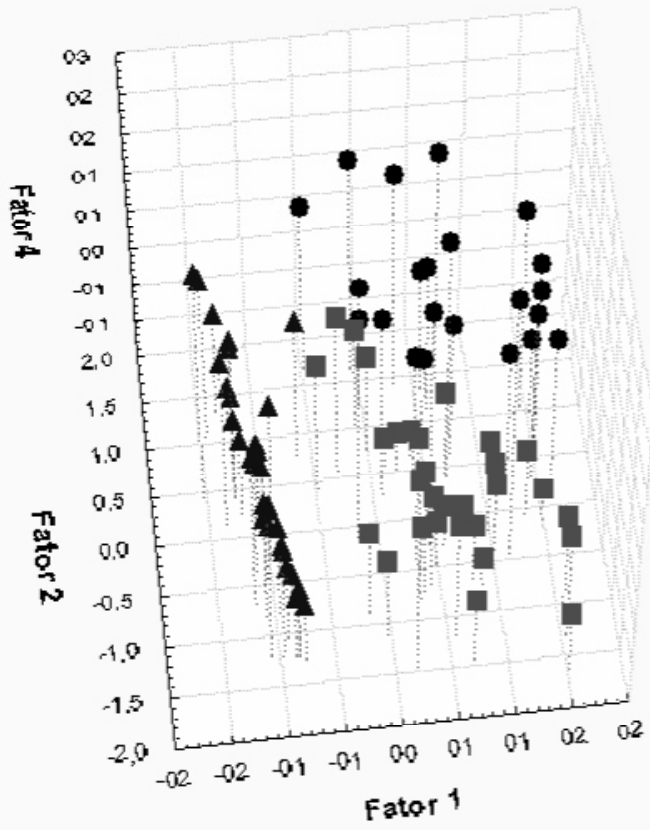

Cluster 1

Cluster 2

4 Cluster 3

Fonte: Pesquisa de campo (2003). Elaboração própria com base no Software STATISTICA 6.0.

A análise multivarida desenvolvida possibilitou identificar os principais fatores que diferenciam as empresas do arranjo, que consistem especialmente na introdução de inovações produtivas e nos esforços de treinamento e capacitação de $\mathrm{RH}$ e de desenvolvimento de atividades inovativas. $\mathrm{Na}$ análise conjunta dos indicadores, ficou clara a existência de três clusters (agrupamentos) de empresas, com características distintas no tocante ao comportamento dos indicadores. As empresas que pertencem ao cluster 1 apresentam os mais elevados indicadores Dessa forma, podemos concluir que os processos relacionados à aprendizagem tecnológica, cooperação, inovação e capacitação de RH são mais intensivos nessas empresas. Por conseguinte, constata-se que, pela elevada intensidade desses processos, as empresas pertencentes ao cluster 1 integram o núcleo de firmas dinâmicas do arranjo. 


\section{O NÚCLEO DINÂMICO DO ARRANJO: SUAS EMPRESAS, SEUS PROCES- SOS DE APRENDIZAGEM, INOVAÇÃO, COOPERAÇÃO E SUAS INTERA- ÇOEES LOCAIS}

A análise desenvolvida na seção anterior caracterizou o cluster de empresas 1 como o núcleo dinâmico do arranjo. As informações obtidas na pesquisa de campo são fundamentais para caracterizar com precisão esse núcleo de empresas no âmbito do arranjo. As tabulações estatísticas das informações do questionário estão disponibilizadas em Stallivieri (2004) e, com base nessas tabulações, pode-se observar que em relação ao tamanho dos estabelecimentos, o núcleo (cluster l) é composto por 5 micro, 7 pequenas, 6 médias e 4 grandes empresas. Do total da amostra investigada, a totalidade das grandes empresas, $75 \%$ das médias, e aproximadamente $17 \%$ das MPEs estão inseridas nesse núcleo. Essas empresas desenvolvem diversas atividades ligadas às indústrias eletrometal-mecânicas, destacando-se a forte presença de firmas que atuam no segmento de bens de capital (68\% das empresas do núcleo), além de dois estabelecimentos no segmento de "metalurgia básica" e cinco empresas ligadas ao segmento de "fabricação de produtos de metal - exclusive máquinas e equipamentos". Sobre o porte e as atividades desenvolvidas pelas empresas, verifica-se, no núcleo dinâmico, a presença tanto de MPEs quanto de médias e grandes empresas atuando em praticamente todos os segmentos de atividades relacionados à indústria em questão, com maior ênfase no segmento de bens de capital.

O principal destino das vendas é o mercado nacional (40,89\%), seguido pelo próprio arranjo $(31,15 \%)$, pelo mercado externo $(16,52 \%)$ e pelo mercado estadual $(11,42 \%)$. Cabe mencionar que as vendas realizadas no espaço local referem-se principalmente a máquinas e equipamentos (bens de capital) que são adquiridos por outras empresas do arranjo. As vendas realizadas no mercado nacional relacionam-se a peças e componentes ${ }^{19}$ que são adquiridos por grandes empresas que atuam no setor automobilístico, além de uma ampla gama de bens de capital para as mais diversas indústrias. A parcela da produção exportada diz respeito, sobretudo, a bens de capital e, em menor escala, a peças e componentes para a indústria automobilística. Finalmente, as vendas que têm como destino o mercado estadual estão relacionadas quase que exclusivamente a bens de capital para diversas indústrias. Portanto, percebe-se que é elevada a participação das vendas desse núcleo de empresas no mercado nacional e externo, assim como os bens vendidos apresentam um elevado conteúdo tecnológico, já que na sua maioria são bens de capital.

19 Peças fundidas em metais ferrosos e não-ferrosos e peças estampadas. 


\subsection{Capacitação de Recursos Humanos, Formas de Aprendizagem e Atividades Cooperati- vas nas Empresas do Núcleo Dinâmico}

No tocante aos processos de treinamento e capacitação de recursos humanos ${ }^{20}$, as empresas pertencentes ao cluster l possuem o indicador mais elevado, praticamente o dobro do valor dos dois outros clusters. Esse fato demonstra que as empresas inseridas neste grupo (cluster $\mathrm{l}$ ) desenvolvem com mais intensidade as diversas atividades associadas a treinamento e capacitação de RH.

Quanto ao aprendizado interno e a sua estruturação ${ }^{21}$, as empresas que pertencem ao cluster 1 mostram os indicadores mais elevados, demonstrando, por um lado, a elevada importância das fontes internas para a aprendizagem e, por outro, que este ocorre com elevado conteúdo de formalização. ${ }^{22}$ Portanto, nas empresas do cluster 1 , além de importante, o aprendizado interno é mais formalizado.

Os indicadores referentes a fontes externas para a aprendizagem refletem a maior utilização e formalização dessas pelas empresas do cluster 1 . Enfatiza-se a elevada utilização de informações obtidas com outros agentes ${ }^{23}(0,68)$ e com agentes produtivos $^{24}(0,5 \mathrm{l})$, e a considerável formalização na troca de tais informações (com indicadores de 0,68 e 0,54, respectivamente), refletindo a existência de acordos formais entre os agentes para o intercâmbio de informações. Um ponto que chama a atenção em relação às empresas deste grupo (cluster 1 ) concerne aos indicadores de aprendizagem relacionados a agentes de ciência e tecnologia. ${ }^{25}$ Os indicadores demonstram que, das empresas do arranjo, as classificadas nesse cluster são as que mais utilizam informações relativas a instituições de pesquisa e capacitação ${ }^{26}$ para o aprimoramento de seu aprendizado, e essa troca de informações é formalizada.

Como demonstrado pelos indicadores referentes à aprendizagem, os processos são mais intensos nas empresas do núcleo dinâmico e, como consequência, percebe-se que os indicadores relacionados a melhorias nas capacitações produtivas, administrativas e mercadológicas também são mais elevados para as empresas do cluster 1 . Assim, para as firmas inseridas neste agrupamento, os processos de treinamento e capacitação de $\mathrm{RH}$ e de aprendizagem geram um impacto maior, elevando tanto as capacitações produtivas quanto as mercadológicas e administrativas.

20 Indicadores apresentados na Tabela Al do Anexo 2.

21 Formal ou informal.

22 A troca de informações no interior das firmas ocorre de maneira formal.

23 Conferências e seminários, feiras e exibições, encontros de lazer, associações empresariais, licenças e patentes e informações na internet.

24 Outras empresas do grupo, empresas associadas, fornecedores de insumos/ equipamentos, clientes, concorrentes, outras empresas do setor e empresas de consultoria.

25 Duas vezes superiores aos demais agrupamentos.

26 Universidades, institutos de pesquisa, centros de capacitação profissional etc. 
Em relação aos processos de aprendizagem, nota-se que as empresas do núcleo dinâmico utilizam com elevada intensidade as fontes internas de informação que circulam com elevado grau de formalização. Daí que, além de relevante, o aprendizado interno nessas empresas assume um caráter formal. No tocante às fontes externas para a aprendizagem, há um elevado esforço das empresas em captar informações que não se limitam às fronteiras do arranjo ${ }^{27}$ e que, em muitos casos, alcançam espaços externos ao próprio país. Esse último aspecto pode caracterizar um conteúdo mais complexo da informação e, portanto, exigir maior capacidade de assimilação da mesma. Essas características dos processos de aprendizagem acabam gerando impactos positivos nas capacitações das empresas, contribuindo, assim, para o aumento da sua competitividade (STALLIVIERI, 2004).

$\mathrm{Na}$ análise dos processos de inovação específicos a cada cluster (Tabela Al, Anexo 2), o indicador referente à constância da atividade inovativa (YE2) demonstra que as empresas inseridas no núcleo dinâmico desenvolvem de forma mais intensa e rotineira as diversas atividades associadas à inovação. $\mathrm{O}$ indicador de inovação relativo à introdução de novos produtos para o mercado internacional e de novos processos para o setor de atuação exibe comportamento similar aos demais indicadores já apresentados. Destacam-se novamente as empresas do núcleo dinâmico (cluster l) com indicador de 0,45 . Cabe assinalar que o valor assumido por este indicador mostra que as empresas do núcleo introduzem novos produtos para o mercado internacional ou novos processos para o setor de atuação.

$\mathrm{O}$ indicador referente à introdução de produtos e/ou processos novos para a empresa, mas que já existem no setor de atuação, demonstra a capacidade de imitação dessas firmas. Percebe-se que para todos os agrupamentos o mencionado indicador é superior ao apresentado anteriormente, reforçando o caráter imitativo que a inovação assume no $\operatorname{arranjo}^{28} \mathrm{e}$, de modo geral, a boa capacitação das empresas locais em imitar produtos e processos novos para as empresas, mas já existentes no setor. Novamente, o indicador mais elevado refere-se ao cluster $1(0,72)$, salientando a elevada capacidade imitativa das empresas do núcleo dinâmico.

Por conseguinte, podemos concluir que as empresas mais inovativas do arranjo estão concentradas no núcleo dinâmico (cluster 1). Elas possuem elevada capacidade de imitação de produtos e processos já existentes e de implementação de inovações organizacionais, além de uma considerável capacidade de introdução de inovações mais "radicais $29 "$ ". Aparentemente, a introdução de inovações gera um impacto posi-

27 Com exceção de outras empresas do setor.

28 Campos et al. (2004).

29 Novos produtos para o mercado internacional e novos processos para o setor de atuação. 
tivo superior nessas empresas, bem como permite que elas atuem em mercados mais competitivos.

Os indicadores referentes aos processos de cooperação das empresas (Tabela Al, Anexo 2) ressaltam que novamente as empresas do núcleo dinâmico (cluster 1) apresentam os mais elevados no que diz respeito ao desenvolvimento de atividades cooperativas e à formalização assumida por tais atividades. Nota-se, entretanto, que esses indicadores mostram valores reduzidos, o que significa que as atividades relacionadas à cooperação são consideradas de baixa importância por essas empresas.

Segundo Stallivieri (2004), percebe-se, em relação à importância das atividades desenvolvidas em conjunto, que o destaque consiste no desenvolvimento de produtos e processos, seguido pela capacitação conjunta de recursos humanos e pela compra conjunta de insumos e equipamentos. Verifica-se, a partir das atividades cooperativas desenvolvidas e dos parceiros envolvidos, que a ação cooperativa das empresas que integram o núcleo dinâmico relaciona-se ao implemento do aprendizado das mesmas, visando ao aprimoramento das capacitações produtivas e à redução dos custos associados ao desenvolvimento de novos produtos e processos.

\subsection{As Interações Locais das Empresas do Núcleo Dinâmico}

Observa-se na análise até aqui desenvolvida a presença no arranjo de um núcleo dinâmico de empresas, no qual os processos de aprendizagem e de inovação são mais intensos, assim como os mercados de atuação dessas empresas são mais amplos que os da esfera local. É significativo o intercâmbio informacional com agentes externos ao arranjo, o que leva a concluir que os spillovers captados pelas empresas do núcleo não se limitam aos espaços locais.

Dadas essas características, quais as relações que esse núcleo estabelece no espaço local? Nas transaçôes comerciais desenvolvidas pelas empresas do núcleo dinâmico no local, destacam-se a aquisição de peças e componentes e a aquisição de serviços no local, demonstrando a elevada importância do arranjo para o funcionamento dessas empresas.

Outro fato característico das empresas do núcleo é sua ação como subcontratantes de outras empresas locais. ${ }^{30}$ Essa característica reforça as relações interindustriais no

30 No tocante à elevada intensidade de relações desenvolvidas com empresas locais, destacam-se os dados apresentados por Stallivieri (2004) em que se verifica, por um lado, a importância das transações comerciais desenvolvidas pelas empresas do núcleo dinâmico no local. Por outro lado, as relaçốes de subcontratação também merecem destaque, já que estas na maioria das vezes requerem uma troca sistemática de informações. Em relação às estratégias de subcontratação desenvolvidas pelas empresas do núcleo dinâmico, verificam-se as seguintes taxas para cada tipo de atividade subcontratada: "fornecimento 
local pelo estabelecimento de redes de cooperação técnico-produtivas com outros agentes do arranjo, na maioria dos casos, coordenando as redes existentes no local (STALLIVIERI, 2004). As grandes e médias empresas do núcleo estabelecem no local suas redes de fornecedores, tanto de materiais diretos ${ }^{31}$ quanto de materiais indiretos/materiais de processos ${ }^{32}$, subcontratando outras empresas locais. As MPEs do núcleo também estabelecem no local, com elevada intensidade, suas cadeias de fornecedores, subcontratando e coordenando as relações com as demais empresas do arranjo.

\subsection{Conclusões sobre o Núcleo Dinâmico e sua Influência para o Arranjo}

A análise multivariada desenvolvida para os indicadores permitiu identificar três agrupamentos de empresas (clusters), e o cluster l é o que agrupa as empresas dinâmicas do arranjo. Observa-se que este núcleo dinâmico não é composto exclusivamente por médias e grandes empresas, sendo significativa a presença de MPEs. Essas empresas atuam em mercados mais competitivos, direcionando suas vendas para o Brasil e para o exterior. Nota-se que as empresas do núcleo atuam em diversas atividades vinculadas às indústrias eletrometal-mecânicas, mas com predominância de produtores de bens de capital, e os produtos gerados por essas empresas possuem um conteúdo tecnológico mais elevado. O Quadro 1 procura resumir as características dos agrupamentos identificados quanto aos processos de aprendizagem tecnológica, cooperação e inovação.

Quanto à dinâmica gerada para o arranjo, pela presença deste núcleo de empresas no local constata-se que elas procuram adquirir, sobretudo no local, peças e componentes, além de serviços. Tais empresas também estabelecem no arranjo suas redes de subcontratação, relacionadas a etapas do processo produtivo, a serviços especializados na produção e para o fornecimento de insumos e componentes. Enfatiza-se que geralmente as empresas do núcleo dinâmico são as que coordenam as redes de cooperação técnico-produtivas existentes no local.

Vale lembrar que a configuração de estruturas em rede leva a um relacionamento mais intenso entre os agentes que integram a rede ${ }^{33}$, materializada numa maior troca

de insumos e componentes" (27,27\% das empresas do núcleo dinâmico subcontratam exclusivamente empresas do arranjo e $36,36 \%$ empresas do arranjo e fora do arranjo); "etapas do processo produtivo" (50,09\% das empresas do núcleo dinâmico subcontratam exclusivamente empresas do arranjo e 13,64\% empresas do arranjo e fora do arranjo) e; "serviços especializados na produção" (45,45\% subcontratam exclusivamente outras empresas do arranjo e $18,18 \%$ empresas do arranjo e fora do arranjo).

31 Peças e componentes que são incorporados aos produtos finais.

32 Materiais indiretos são aqueles utilizados durante os processos produtivos, como por exemplo, moldes, ferramentas e matrizes.

33 Britto (1999). 
de informações sobre produtos e processos. Por conseguinte, a partir da configuração dessas redes locais, coordenadas pelas empresas deste núcleo, observam-se dois movimentos dinâmicos e de sentidos similares. Por um lado, a densa e complexa estrutura produtiva local proporciona às empresas mais dinâmicas constituírem no arranjo suas redes, elevando sua competitividade. Por outro lado, as trocas mais intensas de informações, características dessas estruturas, fazem com que as empresas que não pertencem ao núcleo dinâmico, mas estão inseridas nas redes por elas coordenadas, tenham acesso a spillovers qualitativamente superiores, elevando seus estoques de conhecimento e aumentando sua competitividade.

Constata-se que a presença no local de um núcleo de empresas mais dinâmicas eleva qualitativamente a aprendizagem interativa, característica de arranjos e sistemas produtivos e inovativos locais. O canal construído para que esta forma de aprendizagem qualitativamente superior possa fluir são as redes de cooperação técnico-produtivas existentes no arranjo. Assim, a presença deste núcleo de empresas no local, que coordena as redes técnico-produtivas, acaba por fomentar o aprendizado interativo e possibilita a sustentabilidade do dinamismo do arranjo como um todo. 
QUADRO I - ANÁLISE COMPARATIVA DOS CLUSTERS DE EMPRESAS IDENTIFICADOS NO ARRANJO ELETROMETAL-MECÂNICO DA MICRORREGIÃO DE JOINVILLE/SC

\begin{tabular}{|c|c|c|c|}
\hline Características & $\begin{array}{l}\text { Cluster } 1 \text { (núcleo dinâmico) - } \\
22 \text { Empresas }\end{array}$ & $\begin{array}{l}\text { Cluster } 2 \text { - } \\
30 \text { Empresas }\end{array}$ & $\begin{array}{l}\text { Cluster } 3 \text { - } \\
31 \text { Empresas }\end{array}$ \\
\hline Esforço de treinamento e capacitação de recursos humanos (YE1) & Alto & Baixo & Baixo \\
\hline Importância das fontes internas para a aprendizagem (YA1) & Elevada & Elevada & Elevada \\
\hline Formalização do aprendizado interno (YA2) & Alta formalização & Média formalização & Baixa formalização \\
\hline $\begin{array}{l}\text { Importância das fontes externas para a aprendizagem (YA3, YA5 e } \\
\text { YA7) }\end{array}$ & Média importância & Baixa importância & Baixa importância \\
\hline Formalização da aprendizagem externa (YA4, YA6 e YA8) & Média formalização & Baixa formalização & Baixa formalização \\
\hline $\begin{array}{l}\text { Impacto gerado pelos processos de aprendizagem e de treinamento } \\
\text { e capacitação de } \mathrm{RH} \text { (YD1 e YD2) }\end{array}$ & $\begin{array}{l}\text { Elevado nas capacitações produtivas, } \\
\text { administrativas e mercadológicas }\end{array}$ & $\begin{array}{c}\text { Elevado nas capacitações produtivas, } \\
\text { médio nas capacitações administrativas } \\
\text { e mercadológicas }\end{array}$ & Nulos \\
\hline Esforço de desenvolvimento de atividades inovativas (YE2) & Elevado e constante & Baixo e ocasional & Baixo e ocasional \\
\hline Introdução de inovações "radicais" (YD3) & Média intensidade & Não introduzem & Baixa intensidade \\
\hline Capacidade de imitação (YD4) & Elevada & Média & Média \\
\hline Introdução de inovações organizacionais (YD5) & Elevada intensidade & Baixa intensidade & Baixa intensidade \\
\hline Impacto gerado pela introdução de inovações (YD6) & Forte & Baixo & Baixo \\
\hline Realização de atividades cooperativas (YC1, YC3 e YC5) & $\begin{array}{l}\text { Intensidade média com outros agentes } \\
\text { produtivos e com baixa intensidade } \\
\text { com os demais agentes }\end{array}$ & Baixa intensidade & Não realizam \\
\hline Formalização das relações de cooperação (YC2, YC4 e YC6) & Média formalização & Baixa formalização & - \\
\hline Impacto gerado pelas atividades cooperativas (YD7 e YD8) & $\begin{array}{l}\text { Elevado nas capacitações } \\
\text { produtivas e médio nas capacitações } \\
\text { administrativas e mercadológicas }\end{array}$ & $\begin{array}{l}\text { Médio impacto em ambas as } \\
\text { capacitações }\end{array}$ & - \\
\hline
\end{tabular}

Fonte: Pesquisa de campo (2003). 


\section{CONCLUSÕES}

O exercício proposto neste trabalho, qual seja, utilizar indicadores e a posterior aplicação das técnicas de análise multivariada, permitiu identificar características inerentes à dinâmica inovativa e produtiva de arranjos produtivos locais. No caso em questão, os indicadores e a posterior análise levaram à caracterização de um núcleo de empresas como o "núcleo dinâmico" do arranjo, no qual os processos de aprendizagem, de inovação e de cooperação são mais intensos. Em função do processo de estratificação adotado para a seleção da amostra, que assume a proporcionalidade em relação ao porte e atividade de atuação das empresas e respeita a aleatoriedade na escolha das empresas entrevistadas, as conclusões referentes às 83 empresas que integram a amostra podem ser estendidas para o conjunto de aproximadamente 800 empresas que estão localizadas no arranjo.

Com a identificação do núcleo dinâmico e a subsequente análise das interações desenvolvidas por essas empresas no local foi possível averiguar a influência deste núcleo para a dinâmica produtiva do local. Através dessa análise, procurou-se testar uma metodologia que permite uma caracterização bastante detalhada da estrutura interna daqueles arranjos, a qual possibilita uma representação objetiva da diversidade das formas de governança que é inerente à formação dos mesmos. Ao mesmo tempo, na medida em que tal metodologia possibilita articular a configuração interna desses arranjos a indicadores que contemplam os esforços de aprendizado, o desempenho inovativo e o envolvimento dos agentes com articulações cooperativas, ela oferece uma contribuição objetiva para a caracterização da "dinâmica inovativa" desses arranjos, compreendida como um processo complexo em permanente evolução e transformação. Em termos de uma agenda futura de pesquisa, cabe ressaltar o caráter complementar da análise realizada em relação a outros procedimentos metodológicos que permitem maior detalhamento daquela dinâmica, como por exemplo, a análise e o tratamento estatístico das correlações entre os indicadores considerados e o acompanhamento da evolução dos mesmos ao longo do tempo.

\section{REFERENCIAS}

BANET, A. B.; MORINEAU, A. Aprender de los datos: el análisis de componentes principales. Barcelona, Espanha: EUB, S. L., 1999.

BIDAULT, F. Apprentissage et reseaux. Economies et Societés - Série Dynamique technologique et organization, W.1, n. 5, p. 79-101, mai 1993.

BOUROCHE, J. M.; SAPORTA, G. Análise de dados. Paris, França: Zahar editores S. A., 1980. 
BRITTO, J. N. de P. Características estruturais e modus-operandi das redes de firmas em condiçôes de diversidade tecnológica. 1999. Rio de Janeiro.Tese (Doutorado em Economia) - Instituto de Economia, Universidade Federal do Rio de Janeiro.

; ALBUQUERQUE, E. M. Aglomerações industriais e desenvolvimento local na região Sul: análise exploratória. In: Anais ANPEC/SUL, 2002.

BRYAN, F. J. M. Multivariate statistical methods. Melbourne, Australia: Chapman \& Hall, 1994.

CAMPOS, Renato Campos; STALLIVIERI, Fabio; BATSCHAUER, Jeanine. Arranjo eletrometal-mecânico na microrregião de Joinville-SC: a transição para um sistema produtivo e inovativo local. In: CAMPOS et.al. Programa de Financiamento de bolsas de mestrado vinculadas à pesquisa: micro e pequenas empresas em arranjos produtivos locais no Brasil. CD-ROM. Florianópolis: Editora Fundação J. A. Boiteux, 2004. (Relatório de Pesquisa).

CASSIOLATO, J. E.; LASTRES, H. M. M. O foco em arranjos produtivos e inovativos locais de micro e pequenas empresas. In: LASTRES, Helena Maria Martins; CASSIOLATO, José Eduardo; MACIEL, Maria Lúcia (Org.). Pequena empresa: cooperação e desenvolvimento local. Rio de Janeiro: Relume Dumará. UFRJ, Instituto de Economia, p. 21-34, 2003.

- Inovação, globalização e as novas políticas de desenvolvimento industrial e tecnológico. In: CASSIOLATO; LASTRES (Ed.). Globalização e inovação localizada: experiências de sistemas locais no Mercosul. Brasília: IBICT/MCT, 1999.

COHEN, W.M.; LEVINTHAL, D.A. Innovation and learning: the two faces of R\&D. Economic Journal, v. 99, p. 569-596, 1989.

FERRAZ, J.C; KUPFER, D.; HAGUENAUER, L. Made in Brazil. Ed. Campus, 1996.

JOHNSON, R. A.; WICHERN, D. W. Applied multivariate statistical analysis. 4 ed. Upper Saddle River: Prentice-Hall, 1998.

KUPFER, D.; FERRAZ, J.C.; HAGUENAUER, L. Made in Brazil: desafios competitivos para a indústria. Rio de Janeiro: Campus, 1997.

LASTRES, H. M. M. et al. Interagir para competir: promoção de arranjos produtivos e inovativos no Brasil. Brasília: SEBRAE: FINEP: CNPq, 2002.

LASTRES, H. M. M., CASSIOLATO, J. E. (Coord). Glossário de arranjos e sistemas produtivos e inovativos locais. Rio de Janeiro: IE, 2003.

MALERBA, F. (Ed.) Sectoral systems of innovation. Cambridge, UK: Cambridge University Press, 2004.

; ORSENIGO, L. The dynamics and evolution of industries. Industrial Corporate Change, v. 5, n. 1, 1996.

MALERBA, F. Learning by firms and incremental technical change. The Economic Journal, p. 845-859, July 1992. 
MALHOTRA, N. Pesquisa de marketing: uma orientação aplicada. 3. ed. Porto Alegre: Bookmam, 2001.

REDESIST. Indicadores RedeSist para a avaliação de arranjos produtivos locais. Jul. 2004. Mimeografado.

ROSENBERG, N. La Dirección del cambio tecnológico: mecanismos de inducción y sistemas de enfoque. In: . Tecnologia y Economia. (Tradução em espanhol de Perspectives on Technology, Cap. 6), 1976.

SENKER, J. Tacit knowledge and models of innovation. Industrial and Corporate Change, v. 4, n. 2, p. 425-447, 1995.

STALLIVIERI, F. Dinâmica econômica e a inserção de micro e pequenas empresas em arranjos produtivos locais: o caso da eletrometal-mecánica na microrregião de Joinville/SC. Ago 2004. Dissertação (Mestrado em Economia) - UFSC, Florianópolis, SC.

TEECE, D.; RUMELT, R.; DOSI, G.; WINTER, S. Understanding corporate coherence: theory and evidence. Journal of Economic Behaviour and Organization. North-Holland, 23 , p. 1-30, 1994.

VARGAS, M. A. Aspectos conceituais e metodológicos na análise de arranjos e sistemas produtivos e inovativos locais. Programa de Pesquisa sobre Micro e Pequenas Empresas em Arranjos Produtivos Locais no Brasil. Florianópolis, UFSC, 2002. (Nota Técnica, n. 1)

WHITFORD, J. The decline of a model? Challenge and response in the Italian industrial districts. Economy and Society, v. 30, n. 1, 2001.

YOGUEL, G. Entorno productivo y ventajas competitivas: el caso de uma trama siderúrgica. Pilar: Tag, 2003. 


\section{ANEXO 1 - INDICADORES UTILIZADOS}

Indicadores relacionados a esforço tecnológico:

YEl - Treinamento e capacitação de RH: indicador de esforço relacionado ao treinamento e capacitação de $\mathrm{RH}$.

YE2 - Constância do desenvolvimento de atividades inovativas: indicador de esforço relacionado à forma e constância das atividades inovativas.

Indicadores de aprendizagem tecnológica:

YAl - Aprendizado Interno: indicador de aprendizado interno (learning by doing). Calculado a partir da importância atribuída pela firma às fontes internas de aprendizagem.

YA2 - Estrutura do aprendizado interno: indicador de estruturação do aprendizado interno. Indica a formalização das fontes internas de aprendizagem.

YA3 - Aprendizado externo - agentes produtivos: indicador de aprendizagem externa relacionada a outros agentes produtivos (learning from inter-industy spillovers). Calculado a partir da importância atribuída às fontes externas de aprendizagem.

YA4 - Estrutura do aprendizado externo - agentes produtivos: indicador de estruturação do aprendizado externo derivado de outros agentes produtivos. Indica a formalização das fontes externas de aprendizagem, ligadas a outros agentes produtivos.

YA5 - Aprendizado externo - agentes de C\&T: indicador de aprendizagem externa ligada a fontes de C\&T (learning from advances S\& $T$ ). Calculado a partir da importância atribuída às fontes externas de aprendizagem ligadas à estrutura de C\&T.

YA6 - Estrutura do aprendizado externo - agentes de C\&T: indicador de estruturação do aprendizado externo relacionado à estrutura de C\&T. Indica a formalização das fontes externas de aprendizagem ligadas à estrutura de C\&T.

YA7 - Aprendizado externo - demais agentes: indicador de aprendizado externo ligado a outros agentes. Calculado a partir da importância atribuída as fontes externas de aprendizagem associadas a outros agentes - outras fontes de informação. 
YA8 - Estrutura do aprendizado externo - demais agentes: indicador de estruturação do aprendizado externo ligado a outras fontes de informação. Indica a formalização das fontes externas de aprendizagem vinculadas a outras fontes de informação.

Indicadores de cooperação:

YCl - Cooperação com agentes produtivos: indicador da abrangência de parceiros envolvidos nas atividades cooperativas da firma, que também são agentes produtivos. Calculado a partir da importância atribuída pelas empresas às atividades cooperativas realizadas.

YC2 - Estrutura da cooperação com agentes produtivos: indicador de estruturação das atividades cooperativas desenvolvidas com outros agentes produtivos. Indica a formalização das atividades cooperativas desenvolvidas com outros agentes produtivos.

YC3 - Cooperação com agentes de C\&T: indicador da abrangência de parceiros envolvidos nas atividades cooperativas da firma ligadas a universidades e centros de pesquisa. Calculado a partir da importância atribuída pelas empresas às atividades cooperativas realizadas.

YC4 - Estrutura da cooperação com agentes de C\&T: indicador de estruturação das atividades cooperativas desenvolvidas com universidades e centros de pesquisa. Indica a formalização das atividades cooperativas desenvolvidas com universidades e centros de pesquisa.

YC5 - Cooperação com sindicatos, órgãos de apoio, agentes financeiros e representações: indicador da abrangência de parceiros envolvidos nas atividades cooperativas da firma ligadas a demais agentes. Calculado a partir da importância atribuída pelas empresas às atividades cooperativas realizadas.

YC6 - Estrutura da cooperação com sindicatos, órgãos de apoio, agentes financeiros e representações: indicador de estruturação das atividades cooperativas desenvolvidas com os demais agentes. Indica a formalização das atividades cooperativas desenvolvidas com universidades e centros de pesquisa.

Indicadores de desempenho tecnológico:

YDl - Melhora em produtos e processos: indicador de aprimoramento de capacitações da empresa devido às atividades / processos de treinamento e aprendiza- 
gem. Calculado a partir da importância atribuída pelas empresas à melhora de suas capacitações, em função dos processos de treinamento e aprendizagem.

YD2 - Melhora nas capacidades administrativas e mercadológicas: indicador de aprimoramento de capacitações da empresa devido às atividades/processos de treinamento e aprendizagem. Calculado a partir da importância atribuída pelas empresas à melhora de suas capacitações, em função dos processos de treinamento e aprendizagem.

YD3 - Introdução de novos produtos para o mercado internacional e/ou novos processos para o setor de atuação: indicador de inovação em produtos e processos novos para o setor de atuação.

YD4 - Introdução ou melhorias de produtos e/ou processos novos para a empresa: indicador de inovação em produtos e processos que já existiam no setor de atuação.

YD5 - Introdução de inovações organizacionais: indicador das inovações organizacionais introduzidas pelas empresas.

YD6 - Impacto gerado pela introdução de inovações: indicador de impacto da atividade inovativa. Calculado a partir da importância atribuída pelas empresas ao impacto gerado pela introdução de inovações.

YD7 - Melhora nas capacidades produtivas e organizacionais derivadas dos processos de cooperação: indicador de resultados das parcerias/cooperações realizadas pelas empresas para as capacitações produtivas e organizacionais. Calculado a partir da importância atribuída pelas empresas aos resultados das atividades cooperativas realizadas.

YD8 - Melhora nas capacidades administrativas e mercadológicas derivadas dos processos de cooperação: indicador de resultados das parcerias/cooperações realizadas pelas empresas nas capacitações administrativas e mercadológicas. Calculado a partir da importância atribuída pelas empresas aos resultados das atividades cooperativas realizadas. 
ANEXO 2 - VALOR DOS INDICADORES PARA OS CLUSTERS IDENTIFICADOS TABELA AI - ANÁLISE DE CLUSTER SEGUNDO OS INDICADORES PROPOSTOS PARA AS EMPRESAS DO
ARRANJO ELETROMETAL-MECÂNICO DA MICRORREGIÁO DE JOINVILLE/SC - 2003 (VALORES
REFERENTES À MÉDIA DE CADA CLUSTER)

\section{Indicadores}

Cluster 1-Núcleo Cluster 2 - Cluster 3 - Média para a Amostra Significância*

YE1 - Treinamento e capacitação de RH Dinâmico 22 Empresas 30 Empresas 31 Empresas

- 83 Empresas

YA1 - Aprendizado interno

YA2 - Estrutura do aprendizado interno

0,532323

0,532323
0,847727

0,772727

0,511039

YA3 - Aprendizado externo - agentes produtivos

YA4 - Estrutura do aprendizado externo - agentes produtivos

YA5 - Aprendizado externo - agentes de C\&T

YA6 - Estrutura do aprendizado externo - agentes de C\&T

YA7 - Aprendizado externo - demais agentes

YA8 - Estrutura do aprendizado externo - demais agentes

YD1 - Melhora em produtos e processos

YD2 - Melhora nas capacidades administrativas e mercadológicas

YE2 - Constância do desenvolvimento de atividades inovativas

YD3 - Introd. de novos produtos para o mercado internac. e / ou novos processos para o setor de atuação

YD4 - Introdução ou melhorias de produtos e / ou processos novos para a empresa

YD5 - Introdução de inovações organizacionais

YD6 - Impacto gerado pela introdução de inovações

YC1 - Cooperação com agentes produtivos

YC2 - Estrutura da cooperação com agentes produtivos

0,548701

0,475000

0,630682

0,681818

0,765152

0,781818

0,656818

0,678977

0,454546

0,727273

0,718182

0,621678

0,407792

YC3 - Cooperação com agentes de C\&T

YC4 - Estrutura da cooperação com agentes de C\&T

YC5 - Cooperação com sindicatos, órgãos de apoio, agentes financeiros e representações

0,389610

0,287500

0,340909

0,213636

YC6 - Estrutura da cooperação com sindicatos, órgãos de apoio, agentes financeiros e representações $\quad 0,306818$

YD7 - Melhora nas capacidades produtivas e organizacionais derivadas dos processos de cooperação

0,661818

YD8 - Melhora nas capacidades administrativas e mercadológicas derivadas dos processos de cooperação

0,495568

$0,248519 \quad 0,215054$

0,311245

(Valor p)

\section{$\%$ da amostra}

26,51

$0,651667 \quad 0,545161$

$0,545833 \quad 0,411290$

$0,401905 \quad 0,334562$

$0,364286 \quad 0,311060$

$0,225833 \quad 0,163710$

$0,287500 \quad 0,189516$

$0,531667 \quad 0,418280$

$0,602778 \quad 0,478495$

$0,662222 \quad 0,006452$

$0,498333 \quad 0,019355$

$0,283333 \quad 0,264113$

$0,083333 \quad 0,112903$

$0,333333 \quad 0,374194$

$0,293333 \quad 0,296774$

$0,378718 \quad 0,345906$

$0,302857 \quad 0,000000$

$0,304762 \quad 0,000000$

$0,111667 \quad 0,000000$

$0,116667 \quad 0,000000$

$0,121667 \quad 0,016129$

0,311245
0,663855

0,000000

0,555723

0,000038

$\quad 0,000000$

$0,393288 \quad 0,000000$

$0,268675 \quad 0,000002$

$0,341867 \quad 0,000000$

$0,529116 \quad 0,000000$

$0,599398 \quad 0,000000$

$0,448996 \quad 0,000000$

$0,361446 \quad 0,000000$

$0,381024 \quad 0,000000$

$0,192771 \quad 0,000027$

$0,453012 \quad 0,000000$

$0,407229 \quad 0,000000$

$0,430862 \quad 0,000001$

$0,217556 \quad 0,000000$

$0,213425 \quad 0,000000$

$0,116566 \quad 0,000000$

$0,132530 \quad 0,000000$

$0,106627 \quad 0,000027$

$\begin{array}{llll}0,170833 & 0,016129 & 0,149096 & 0,000010\end{array}$

$\begin{array}{llll}0,397333 & 0,012258 & 0,323614 & 0,000000\end{array}$

Fonte: Pesquisa de campo (2003).

* Utiliza-se o valor $p$. Considera-se que existe uma diferença significativa entre os clusters, a um nível de significância de $5 \%$, apenas nos indicadores em que a probabilidade do valor $p$ é inferior a $5 \%(0,05)$. 